\title{
EDUCAÇÃO INFANTIL: ANÁLISE DA MANIFESTAÇÃO SOCIAL DO PRECONCEITO NA ATIVIDADE PRINCIPAL DE JOGOS
}

\author{
Gustavo Martins Piccolo*
}

\begin{abstract}
RESUMO: Este artigo se configura como a síntese de minha dissertação de mestrado, tendo como objetivo geral discutir sobre o processo de apropriação, desenvolvimento e crítica das manifestações preconceituosas expressas por pré-escolares na prática de sua atividade principal. A pesquisa se orientou por pressupostos do materialismo histórico, na perspectiva histórico-cultural de Vygotsky, e a coleta de dados foi realizada em uma pré-escola pública. Os resultados obtidos apontaram para a existência de manifestações preconceituosas relacionadas às categorias gênero, raça e beleza; além de destacar a importância assumida pela mediação docente na contestação destas atitudes e na compreensão da diferença não como desigualdade, mas como a expressão histórica da humanidade, contida nas mais diversas culturas, sociedades e seres humanos.
\end{abstract}

Palavras-chave: Preconceito. Atividade. Mediação. Teoria histórico-cultural.

\section{Preschool education: AN ANALysis of the SOCIAL MANIFESTATION OF PREJUDICE IN GAMES}

\begin{abstract}
This paper is a synthesis of the author's master thesis, which discusses the process of appropriation, development and critics of the manifestations of prejudice by preschoolers in the practice of their main activity. It is oriented by assumptions of historical materialism, according to Vygotsky's historical-cultural perspective. Data were collected in a public preschool. Results point out the existence of manifestations of prejudice related to the categories gender, race and beauty. They also highlight the importance of teacher's mediation to contest such attitudes and understand differences as the historical expression of the humanity contained in the most diverse cultures, societies and human beings rather than inequalities.
\end{abstract}

Key words: Prejudice. Activity. Mediation. Historical-cultural theory.

\section{ÉDUCATION INFANTILE: ANALYSE DE LA MANIFESTATION SOCIALE DU PRÉJUGÉ DANS L'ACTIVITÉ PRINCIPALE DE JEUX}

RÉSUMÉ: Cet article est une synthèse de mon mémoire de master, dont l'objectif général est de discuter le processus d'appropriation, de développement et de

\footnotetext{
* Doutorando em Educação Especial pela Universidade Federal de São Carlos (UFSCAR) e professor de Educação Física da rede estadual de Educação do estado de São Paulo. E-mail: gupiccolo@ yahoo.com.br
} 
critique des manifestations de préjugés exprimées par des enfants en âge préscolaire dans la pratique de leur activité principale. Cette recherche est orientée par des présupposés du matérialisme historique, dans la perspective historico-culturelle de Vygotski, et les données proviennent d'une école maternelle publique. Les résultats révèlent l'existence de manifestations de préjugés liées aux catégories genre, race et beauté; ils mettent en outre en relief l'importance assumée par la médiation enseignante et dans la contestation de ces attitudes et dans la compréhension de la différence non pas comme inégalité, mais comme expression historique de l'humanité contenue dans les plus diverses cultures, sociétés et êtres humains.

Mots-clefs: Préjugé. Activité. Médiation. Théorie historico-culturelle.

\section{Introdução}

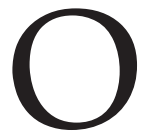

presente trabalho discute o desenvolvimento de manifestações preconceituosas nas relações entre pré-escolares de 5 e 6 anos durante a prática de sua atividade principal: os jogos protagonizados ou brincadeiras, a partir de pressupostos materialista-históricos, principalmente aqueles inspirados pela psicologia histórico-cultural, cujos grandes expoentes são Vygotsky, Leontiev, Luria e Elkonin.

Ancorados em Marx $(1987,1996)$, partimos cientificamente da definição do homem como um ser social, coletivo e histórico, cujo processo formativo deriva do complexo sistema de relações desenvolvidas pelo trabalho e pela linguagem, os quais nos possibilitaram uma inserção ativa e transformadora perante a realidade circundante. Tais relações, em conjunto, compuseram a sociedade e a cultura, pressupostos basilares em todo o complexo epistemológico desenvolvido pela escola de Vygotsky.

A longa história de domínio do homem sobre a natureza, mediante a criação de instrumentos artificiais (signos e ferramentas), edificou um conjunto de relações simbólicas e materiais que orientam e, de certa forma, condicionam a inserção dos mais diversos sujeitos no tecido histórico da sociedade, cuja aprendizagem não se dá de maneira individual ou espontânea, se tratando essencialmente de um processo educativo.

Por todas essas características, para o homem não basta simplesmente se reproduzir como espécie, uma vez que precisa se apropriar das conquistas alcançadas por todas as gerações anteriores para se inserir ativamente no cenário da história. Essas apropriações necessitam, de acordo com Vygotsky (1993), de um conjunto de atividades que nos coloquem em contato com as produções materiais e simbólicas edificadas pela humanidade. Apenas por intermédio de seu desenvolvimento o homem alcança na ontogênese o que o animal consegue pela hereditariedade (Marx, 1972), porém, ao contrário dos animais, que se adaptam à realidade, os seres humanos a transformam teleologicamente. 


\section{A categoria de atividade}

O conceito de atividade na teoria histórico-cultural foi desenvolvido, principalmente, por Leontiev (1978a, 1978b, 1988), mas também por Vygotsky $(1995,2001)$, Davidov (1988) e Elkonin (1987). De forma sucinta, Leontiev (1988, 1978a) destaca que o conceito de atividade pode ser entendido como um tipo de mediação concretizado em relação à realidade externa. Por intermédio de sua atividade, o homem se relaciona com o mundo, apropriando os capitais conhecimentos componentes de sua realidade, além de satisfazer suas principais necessidades físicas, materiais, espirituais e culturais.

Neste artigo, apesar de não tecermos todas as considerações sobre a estrutura da categoria de atividade desenvolvida pela escola de Vygotsky, a qual a entende como um complexo processo envolto por outros componentes como as ações, os motivos, e as operações, destacamos o fato de a psicologia histórico-cultural ter alavancado enriquecedoramente a definição do conceito de atividade expresso por Marx (1996), o qual, devido a seus objetivos epistemológicos, se dedicou fundamentalmente à explanação de "apenas" uma entre outras atividades humanas, a citar: o trabalho, realizado de forma basilar na idade adulta. Todavia, os seres humanos, desde seu processo de nascimento, executam atividades para se apropriar e se enraizar dos e nos principais componentes de sua realidade externa. Por isso, segundo Leontiev (1978b), em cada estádio do desenvolvimento psíquico existe um conjunto de atividades pela qual entramos em contato com a realidade externa. A atividade cujo desenvolvimento possibilita a inserção e a apropriação dos principais componentes dessa realidade denomina-se atividade principal. Para Leontiev (1988), esta se caracteriza por, em determinado estádio, exercer uma maior influência no desenvolvimento psicológico e social do ser humano, na medida em que promove profundas alterações nos mecanismos construtores de nossa personalidade.

Ainda de acordo com Leontiev (1978b), algumas atividades que são as principais em determinados estádios de desenvolvimento não o são em outros, passando a representar papéis subsidiários no processo de desenvolvimento humano. Indubitavelmente, uma criança de 1 ano não se apropria da realidade de maneira similar a outra de 5 anos, tampouco da mesma forma que o adulto. Por conseguinte, o estádio de desenvolvimento psíquico em que a pessoa se encontra, o qual recebe a interferência de diferentes fatores, tais como os níveis etários, sociais e culturais, possui como elemento determinante o tipo de mediação desempenhada, em relação à realidade externa, pela atividade principal.

Enriquecendo esta contribuição de Leontiev (1978a), Davidov (1988) delimita as atividades características de cada estádio de desenvolvimento humano. A etapa inicial (0 e 1 ano de idade) é marcada pelo forte contato emocional dos bebês com 
os adultos, todas as suas necessidades físicas, lúdicas e sociais são satisfeitas pelos adultos. A segunda etapa (1 e 3 anos de idade) tem como atividade principal a manipulação de objetos; nesta fase a criança já consegue se locomover sem o auxílio do adulto e conhece o mundo por intermédio da exploração objetal. A terceira etapa, considerada como pré-escolar ( 3 aos 6 anos), possui nos jogos protagonizados ou brincadeiras sua atividade principal e eles são os responsáveis pela inserção da criança na realidade social e pela apropriação de seus principais conhecimentos e estruturas; esta atividade se efetiva de forma lúdica e dramatizada. Já na quarta etapa (6 aos 10 anos), o estudo escolar passa a ser a atividade principal, por possibilitar a apropriação de conhecimentos científicos e sistematizados; na adolescência, a comunicação entre coetâneos (atividade principal) é a responsável pelas principais alterações nos mecanismos construtores da personalidade. Por fim, a fase adulta tem no trabalho sua atividade principal, cuja gênese reside na transformação da natureza a partir de idealizações pré-estabelecidas.

\section{A atividade principal dos pré-escolares}

O estádio de desenvolvimento que vai dos 3 aos 6/7 anos é denominado de pré-escolar por Leontiev (1988), Davidov (1988) e Elkonin (1998, 1987), apresentando como atividade principal os jogos protagonizados ou brincadeiras de faz de conta. Para Leontiev (1988), designamos a expressão "atividade principal" para a atividade frequentemente encontrada em dado nível no desenvolvimento do ser humano, a qual promove as maiores transformações em seus mecanismos psicológicos, e não àquela praticada durante a maior parte do tempo. Atividade em conexão com a qual ocorrem as mais importantes mudanças no desenvolvimento social, intelectual e motor da criança, e dentro da qual se enriquecem processos psicológicos que preparam o caminho de transição da criança para um novo e mais elevado nível de desenvolvimento.

No estádio pré-escolar, é mediante os jogos protagonizados e brincadeiras que as crianças se apropriam das principais ações realizadas pelos adultos na sociedade. São eles que promovem a construção de um relacionamento da criança com o mundo de forma mais ampla, já que não apenas as ações diretamente acessíveis a ela são reproduzidas, pois, mediante suas dramatizações, a criança passa a se apropriar de forma ativa e efetiva das principais conquistas obtidas por todo o gênero humano, como o trabalho, a arte, o lazer, a ciência (Leontiev, 1988).

Estas influências recebidas pelas crianças durante o período pré-escolar são fundamentais para a complexificação e ampliação de seus movimentos exploratórios e nos auxiliam na compreensão de que esta complexificação se dirige tanto em termos psicológicos, na medida em que torna os movimentos voluntários e 
conscientes, como em termos efetivamente motores, por possibilitar uma maior flexibilidade, coordenação, agilidade, velocidade e amplitude nos movimentos realizados, aumentando, assim, as possibilidades de inserção e apropriação de distintas tarefas sociais realizadas nas esferas cotidianas.

Tal inserção é de tal forma completa que, na pré-escola, as crianças se apropriam, mediante seus jogos protagonizados e brincadeiras, de uma vasta gama de conceitos e relações sociais expressos na realidade que as circunda. Logo, estas relações podem se embasar tanto em pressupostos solidários e democráticos, bem como, em sociedades hierárquicas e estratificadas, ser pautadas em estereótipos, na discriminação e exclusão da diferença e na não valorização de uma relação dialógica no processo de comunicação humana.

Dessa forma, nem todas as apropriações por nós internalizadas atuam como fatores propulsores em nosso desenvolvimento, uma vez que algumas significações elaboradas historicamente se estruturam sobre pressupostos opressivos, discriminatórios e egoístas, cuja funcionalidade reside na exclusão e no estreitamento de possibilidades oferecidas aos seres humanos. Neste campo, as manifestações preconceituosas encontram um terreno fértil para se propagarem e interferirem negativamente no local ocupado por cada sujeito na complexa teia das relações sociais.

\section{Sobre o preconceito}

O preconceito é um fenômeno tão difundido quanto mal interpretado. Vários autores (Heller, 1970; Jones, 1973; Bastide \& Fernandes, 1955; Ferreira, 1986), que retrataram este tema com diversos olhares, nos ajudam a ampliar a visão sobre este fenômeno. O dicionário Aurélio (Ferreira, 1986, p. 1380) o define como "um conceito de opinião formada antecipadamente, sem maior ponderação ou conhecimento dos fatos; ideia pré-concebida. Julgamento ou opinião formada sem levar em conta o fato que o conteste".

A visão do autor define, em nossa opinião, o que seria o pré-conceito e não o preconceito, pois o conceito de preconceito, além dos elementos ora descritos, recebe outros contornos que o demarcam como um fenômeno humano discriminatório e alienante, tais como: a qualificação pejorativa de tudo o que difere de determinado modelo social tido como hegemônico, mediante a arquitetura de um conjunto de estereótipos, os quais são incorporados nos mais diversos processos comunicativos desencadeados cotidianamente; e a manutenção dos estereótipos pejorativos contra determinado grupo, mesmo quando a prática não o comprove, ou o refute.

Na prática preconceituosa, estes estereótipos são mantidos não apenas quando deixamos de levar em consideração os fatos que o contestem, mas, inclusive, 
quando temos conhecimento destes fatos. Por isso, mais do que uma fase de pré-conhecimento ou de uma opinião formada antecipadamente, o preconceito representa uma cristalização inverídica de determinado conhecimento e sua adequação a interesses ideológicos dos grupos dominantes. Exatamente devido a estas características, a transformação de seu complexo estrutural se mostra uma tarefa extremamente árdua, cujos frutos não são colhidos em curto prazo, uma vez que seus alicerces gnosiológicos já se encontram cristalizados, petrificados.

Em circunstâncias especiais, como nas discriminações efetuadas sem que tenhamos a real compreensão dos motivos que engendram nossas atitudes, o preconceito em muito se assemelha ao pré-conceito, mas apenas no sentido de que a generalização de determinado fenômeno social carece em níveis mais elevados de abstração, pois, no preconceito, essas generalizações se direcionam não para a apropriação da realidade circundante (como no pré-conceito), mas visando à discriminação e exclusão da diferença. Ou seja, as generalizações preconceituosas propagam-se e fixam-se de maneira indevida e equivocada do ponto de vista da lógica dialética.

Assim, destacamos que a similaridade existente entre o pré-conceito e o preconceito edifica-se superficialmente, se ancorando, ainda que de maneira falaciosa, em determinado estádio do pensamento preconceituoso (sua fase embrionária) como se este fosse o único presente, desconsiderando suas múltiplas gradações, as quais podem se manifestar desde sua vertente embrionária (fase característica das atitudes discriminatórias inconscientes, encontrada já na pré-escola, e, por sua aparência externa, assemelha-se aos pré-conceitos) até as formas cristalizadas e dogmáticas, sendo que em muito diferem as estruturas psicológicas destas gradações e de uma etapa para outra. Ou seja, não há uma única gradação do preconceito, mas um complexo sistema de deturpação simbólica e material que se mostra extremamente mutável, devido às variações do meio e de cada sujeito considerado em particular. Dito isto, passemos agora a caracterizar mais detalhadamente a composição e estrutura da manifestação social entendida como preconceito.

Para Jones (1973), o preconceito é um juízo prévio e negativo dos componentes de uma raça, religião, condição social, mantido sobre os fatos que o contradizem. É um modo acrítico do pensamento pessoal que desemboca em um julgamento errado e equivocado de outros grupos/culturas sociais, configurando-se como um conceito generalizador que imputa para toda a sociedade os valores que devem ser aceitos ou não em determinada esfera cotidiana.

Bastide e Fernandes (1955) destacam que, devido ao seu caráter ideológico, o preconceito regula as relações dos indivíduos com seu meio externo (sociedade) e interno (consciência). Por isso, apesar de não ser um componente imediato da estrutura social, o preconceito interfere objetivamente no ajustamento dos seres humanos 
nos postos de trabalho e na posição social ocupada pelos sujeitos em situações que se repetem cotidianamente. Coerentemente, o preconceito não é apenas um julgamento prévio, mas um julgamento prévio negativo e ideológico que estigmatiza, por meio de estereótipos, as pessoas que diferem do conjunto de arquétipos configurados como dominantes.

Apesar de o preconceito afetar todos os grupos sociais, uma vez que limita e estreita os horizontes de ações e possibilidades de desenvolvimento das funções psíquicas superiores do homem, é sobre os grupos discriminados que ele incide seu maior peso opressivo e exploratório, posto que transforma suas diferenças em desigualdades e exclusão social. Em virtude destes elementos, a contestação do preconceito desde a mais tenra idade se mostra como um elemento fundamental na transformação das relações sociais e comunicativas estabelecidas pelos seres humanos, sendo que sua materialização produz ganhos em todas as esferas do desenvolvimento humano, sejam psíquicas, motoras, gnosiológicas, sociais ou culturais, as quais estão em constante interrelacionamento.

Este fato reitera a importância crucial da realização de intervenções mediativas críticas que impeçam que os conhecimentos apropriados pelos seres humanos, desde a mais tenra idade, atinjam o estádio de dogmatismo peculiar das relações embasadas em pressupostos preconceituosos e, porventura, transformem possíveis ideias dogmáticas expressas pelas crianças a partir da historicização dos fenômenos socialmente construídos.

A proficuidade na crítica ao preconceito realizada no estádio pré-escolar está relacionada ao fato de que, nesta fase de desenvolvimento, com raras exceções, os conhecimentos apropriados pelas crianças não se encontram sob uma vertente cristalizada, apresentando possibilidades favoráveis à transformação de sua estrutura, conteúdo e relação social, ou seja, a alteração da relação existente entre o significado e o sentido de determinado conhecimento. Porém, esta transformação conceitual e atitudinal não pode ser efetivada em sua plenitude quando as crianças agem autonomamente, necessitando de elementos que elevem a qualidade crítica dos pensamentos, ideias e relações sociais vivenciadas por elas para além das esferas cotidianas, adentrando, assim, em um novo universo de relações inalcançável para a criança que age sozinha, denominado por Vygotsky (2001) de "zona de desenvolvimento proximal”.

Por conseguinte, o desenvolvimento, a reprodução e a contestação dos preconceitos em nossa sociedade estão ligados, além da modificação da base material que estrutura a sociedade, à qualidade dos processos educacionais por que passa cada sujeito. Se entendermos que o preconceito é um conceito que expressa um conjunto de relações sociais arquitetadas de maneira hierárquica e dogmática, as quais coadunam no estreitamento das possibilidades de apropriações sócio-culturais daqueles 
grupos que diferem dos modelos dominantes e se sustentam pela naturalização de seus pressupostos e justificativas; então, a educação sistematizada constitui-se como uma das principais atividades para sua contestação, a qual, através de um conjunto de mediações críticas, vise à superação deste fenômeno aceito, muitas vezes, sem quaisquer críticas e tomado como um sistema de verdades eternas, baseado em premissas justificadoras e naturalistas.

\section{Procedimentos metodológicos}

O objetivo geral da pesquisa consistiu em levantar indicativos de manifestações preconceituosas em crianças pré-escolares de 5 e 6 anos, na prática de sua atividade principal. Para isso, nos valemos de uma tríade de objetivos auxiliares ou específicos: 1) observar e analisar como as crianças se interrelacionam durante a execução dos jogos e brincadeiras; 2) investigar como tais atividades influenciam na apropriação e/ou contestação de preconceitos; 3) explicitar como as mediações estabelecidas pelas professoras exercem interferência no tipo de relação social assumida entre coetâneos.

O palco desta pesquisa foi uma pré-escola situada em uma pequena cidade no interior do estado de São Paulo, localizada próxima à região de Araraquara. Como instrumento metodológico para a obtenção dos dados, utilizamos observações, filmagens e conversas entre as crianças (anotadas em um diário de campo), no período em que brincavam livremente pelo parque da unidade pré-escolar. As expressões "brincadeiras livres" e "jogos livres" representam, neste trabalho, as atividades lúdicas realizadas no interior das pré-escolas em que tanto a proposição, como o desenvolvimento e término da atividade são regulados pelas próprias crianças e não pela intervenção docente. Assim, neste escopo teórico, "livre" não deve ser interpretado como se as brincadeiras e jogos fossem desprovidos de mediações ou de componentes/conteúdos reguladores externos, tampouco que surjam deslocadas de alguma relação social, mas apenas que os principais motivos que engendram a realização das atividades sejam edificados por seus próprios participantes. Além disso, as intervenções das professoras também se constituíram como um interessante espaço de análise, principalmente pela introdução de questionamentos sobre algumas atitudes presenciadas na comunicação entre os pré-escolares.

Os dados coletados foram divididos em pequenos excertos (os quais retratam o contexto e a maneira em que se desenvolviam as atividades lúdicas, contendo a descrição do jogo ou brincadeira e, porventura, também a fala das crianças e das professoras) e analisados individualmente mediante quatro categorias, quais sejam: mediação, preconceito de gênero, preconceito de raça e preconceito de beleza. As denominações das categorias gênero, raça e beleza antecedidas pelo substantivo preconceito 
deveram-se ao fato de, nesta pesquisa, não trabalharmos sociologicamente os conceitos em si de gênero, raça ou beleza, mas de analisarmos como estes elementos se configuram como nexos mediativos na construção de manifestações preconceituosas. Assim, procuramos entender como o elemento gênero, bem como a raça e a beleza se encontram presentes na produção do preconceito em pré-escolares, mas não como categorias de análise isoladas.

\section{Resultados e análises}

Os resultados obtidos em nossa pesquisa apontam para a existência de manifestações preconceituosas nas atividades lúdicas realizadas pelos pré-escolares, as quais limitam radicalmente as apropriações gnosiológicas, corporais e, consequentemente, culturais oferecidas para todos os alunos e alunas envolvidos no processo de educação escolar. Além disso, os dados testemunham acerca da importância assumida pela intervenção docente e pela transformação da estrutura estabelecida pelas atividades lúdicas na pré-escola, visando à contestação de possíveis relações sociais preconceituosas e verticalizadas desempenhadas no contato entre as crianças. Tal intervenção é justificada pelo fato de, em situações sociais "espontâneas", tais como nas atividades lúdicas comandadas pelos próprios participantes, as crianças se relacionarem, por diversas vezes, embasadas por pressupostos discriminatórios; principalmente, naquelas atividades em que a vitória e a derrota representam o coroamento de sua prática. Alguns destes elementos podem ser presenciados no excerto a seguir, que acreditamos ser significativo na demonstração do processo de exclusão e rotulação pela qual a diferença é vista desde a pré-escola:

Sempre mais competitivos e excludentes, os meninos justificavam a não aceitação das meninas em seu grupo como estando relacionada à falta de habilidade destas na realização dos jogos esportivos. Pedro achava impossível jogar futebol com Samanta (a qual sempre queria jogar), já que todas as meninas eram muito ruins e atrapalhariam o jogo, essa opinião foi compartilhada por Hugo, Jorge, Renato e José. Após a recusa veemente dos meninos quanto à inserção de Samanta no jogo de futebol, a aluna pegou uma bola e ficou brincando sozinha até que a professora interveio na situação, persuadindo os meninos a deixarem Samanta jogar com eles (nesta intervenção, a professora, sem especificar o motivo da paralisação da aula, reuniu as crianças e estabeleceu que qualquer criança participaria da atividade que bem entendesse, e "o primeiro que não deixar algum coleguinha participar de seu jogo também não irá jogar, chega de briguinhas, todo mundo está aqui para se divertir" [palavras da professora]). Logo após o início do jogo, Samanta se mostrou a melhor jogadora da partida, marcando vários gols, dando bons passes etc. Enfim, a menina anteriormente chamada de perna de pau se transformou na "Ronaldinha" pela designação dos próprios colegas. Porém, o mais interessante ocorreu posteriormente ao jogo, pois Hugo e Jorge, ambos representantes do time derrotado, sem perceberem a presença do pesquisador, comentavam sobre a importância de não deixar mais Samanta jogar, já que todos sabiam que ela era a melhor da classe e os 
envergonhariam durante a partida, “o que não pega bem para nós, onde já se viu, perder para menina, vai...". (Palavras transcritas de Hugo)

A fala de Hugo (um garoto de 6 anos) contém os elementos principais do que consideramos uma atitude efetivamente preconceituosa, a qual não se refere a uma simples generalização, mas a uma generalização indevida e inverídica que não se comprova empiricamente e, mesmo assim, se mantém intacta. Também percebemos como as manifestações preconceituosas são utilizadas objetivando manter incólumes a hierarquia e a hegemonia existentes nas relações entre pessoas que desfrutam de posições sociais distintas, na inserção em determinada atividade ou contexto histórico, como é o caso da mulher na prática do futebol. Esta hegemonia impede a ascensão dos grupos considerados como dominados para outro patamar qualitativo, no que tange ao desenvolvimento de suas habilidades.

Hugo sabia que Samanta jogava muito bem e, contraditoriamente, a chamava de perna de pau, dizia que ela estragaria o jogo, pois meninas não poderiam jogar junto com os meninos. Assim, mesmo sabendo de todo o potencial de Samanta, Hugo fez de tudo para que ela não jogasse, atitude esta aceita quase sem exceção pelos meninos e que foi refutada somente pela intervenção da professora, que praticamente obrigou a aceitação de Samanta no jogo e possibilitou a mudança de opinião da maioria dos meninos sobre o desempenho de menina no jogo. Porém, Jorge ainda continuava achando que meninas obrigatoriamente jogariam mal o futebol, pois "o problema estava com Samanta, e não com as outras" (palavras de Jorge, 6 anos). Esse fato demonstra como alguns raciocínios podem se cristalizar desde a mais tenra idade e reitera como, na prática cotidiana do futebol, a sociedade não encara da mesma maneira o fato de um menino e uma menina serem hábeis nesta prática esportiva. No primeiro caso, temos a regra; no segundo, a exceção. Coerentemente, para Jorge, o problema realmente estava com Samanta.

Para Souza e Altmann (1999), desde o seu surgimento, algumas atividades esportivas, como o futebol, o basquete e o judô, eram praticadas apenas pelos homens por representarem esportes que exigiam maior esforço, confronto corpo a corpo e movimentos violentos. Assim, o futebol, esporte violento, tornaria o homem viril e, se fosse praticado pela mulher, poderia masculinizá-la, tal qual a prática do balé e das danças, cujo desenvolvimento preza pela graciosidade e fragilidade que perpassam a construção do corpo feminino e exerceria efeito deletério sobre a virilidade e robustez masculina. Essas ideias explicam alguns dos estigmas formulados contra homens e mulheres na prática de atividades lúdicas. Sobre comportamentos como esses, cuja presença contraria as expectativas construídas sobre o que é ser menino e menina cotidianamente, há o peso de toda uma sociedade que marginaliza e discrimina a diferença como sinal de desigualdade, esquisitice e elemento a ser corrigido. 
Essa arquitetura segregacionista não passa incólume aos olhos das crianças, que se apropriam dessas estratificações como verdades absolutas, quando não há uma contraposição dialética com outro sistema conceitual, e as transferem para seus relacionamentos e práticas diárias, tal como foi observado em Hugo e Jorge ao jogarem futebol juntamente com Samanta. Por conseguinte, as atitudes discriminatórias de Hugo e Jorge não se constituem em um vácuo histórico isolado do mundo, denotando certo componente da sociedade refletido em suas estruturas psíquicas, gnosiológicas e comunicativas. Assim, não podemos nos esquecer, como nos lembra Vygotsky (2004), de que o ser humano só se torna singular a partir da influência de outras pessoas e do ambiente externo. A criança, apesar de estar na sociedade desde que nasce, precisa se apropriar de um conjunto de elementos para se individualizar. Por isso, só existe individualidade a partir da coletividade, ninguém se humaniza isolado das relações sociais.

Todavia, apesar de a sociedade influenciar decisivamente a construção do comportamento humano, não se pode esquecer que são os próprios homens que a produzem e a transformam diariamente. Coerentemente, sua estrutura e valores não são eternos, tampouco universais, mas historicamente situados em contextos sociais, culturais e materiais específicos. Por todas essas características, a historicização das desigualdades (econômicas, culturais, étnicas, religiosas, estéticas, raciais, de gênero, beleza, habilidades atléticas, entre outras) se edifica como um interessante espaço pedagógico para o questionamento das manifestações preconceituosas, sendo que os jogos e brincadeiras realizados na pré-escola, desde que criticamente mediados, podem representar o palco de importantes desconstruções dogmáticas e da transformação de algumas relações sociais verticalizadas e assimétricas, como demonstra o excerto anterior; ainda que a intervenção docente não tivesse explorado, em sua plenitude, a historicização dos fenômenos sociais e a importância no convívio com as diferenças ao desenvolvimento unilateral dos seres humanos.

Deste exemplo, vários outros podem ser retirados a partir de nossa dissertação de mestrado, relacionados às categorias gênero, beleza, raça, padrões estético-corpóreos. Todavia, não foram retratados neste momento devido à limitação do número de páginas do artigo.

De forma geral, nossa pesquisa demonstrou que o início de toda e qualquer manifestação preconceituosa pressupõe a desvalorização das diferenças apresentadas por cada grupo/sujeito considerado em particular, em relação ao conjunto de elementos estabelecidos como dominantes pela sociedade e que pode abranger uma multiplicidade de vetores. A desvalorização das diferenças começa a se materializar, efetivamente, naquilo que podemos categorizar como preconceito (ou fase embrionária do preconceito), quando estas diferenças se transformam em desigualdades e passam a ser encaradas como motivos justificadores da não inserção das pessoas 
que as apresentem em determinada atividade, como foi observado com Samanta. Por fim, a incorporação e internalização do preconceito nas relações sociais se dão quando, além da classificação pejorativa da diferença e de sua transformação em desigualdade, a desconstrução empírica e fidedigna dos estereótipos e das justificativas que sustentam estas manifestações não é suficiente para a transformação de suas relações, ou seja, quando a rotulação das diferenças se torna um pensamento dogmático e cristalizado.

Assim, o ciclo pelo qual se compõem as manifestações preconceituosas é constituído por três fases, sendo que na pré-escola, com raras exceções (como a fala de Hugo), apenas as duas primeiras efetivamente se materializam nas atividades lúdicas, fato que demonstra quão importantes são as mediações educacionais para impedir que o ciclo do preconceito realize todo seu percurso opressivo e discriminador. Este ciclo, depois de fechado, tende a resistir mesmo a empreitadas mediativas críticas, que poderiam desmantelar toda sua estrutura.

A forma de impedirmos o fechamento deste perigoso ciclo na escola passa inevitavelmente pela valorização das diferenças, mas também pelo fato de nenhum aluno ou aluna ser excluído de qualquer prática social, seja ela lúdica, artística etc., e sobretudo pela historicização crítica dos mais diversos fenômenos e constructos sociais, cuja finalidade reside em obstruir a cristalização do pensamento humano, o qual não deve se embasar em dogmas, mas em conceitos que estão em contínuo processo de transformação. Este é o árduo trabalho a ser realizado pelas professoras na pré-escola, com a complicação de a historicização gnosiológica neste estádio de desenvolvimento não poder ser realizada apenas abstratamente, necessitando de vínculos práticos com a situação representada, bem como de um envolvimento das professoras na própria conjuntura destes acontecimentos que seja amplo, mas que não transforme o ensino na pré-escola em um processo de escolarização precoce; por isso, a importância assumida pelas atividades lúdicas na configuração de um currículo que anseie formas democráticas de comunicações interpessoais.

Desse modo, as relações verticalizadas desempenhadas pelos pré-escolares em situações sociais "espontâneas" são relações apropriadas mediante um moroso processo educacional, ou seja, nada têm de espontâneas. Este processo, por estar situado historicamente, faz com que as crianças, ao se apropriarem dos principais conhecimentos produzidos pela sociedade da qual fazem parte, também se deparem com todas as agruras características desta estrutura social hodierna, tais como: a segregação, o racismo, a xenofobia, o machismo, a rigidez nos padrões estético-corporais, a desigualdade econômica, cultural, política e educacional.

Contudo, a dialética contida neste mesmo processo fez com que, em algumas situações coordenadas pelas próprias crianças, várias atitudes cooperativas fossem observadas nas atividades lúdicas quando estas não eram direcionadas 
para a supressão dos adversários, tais como a união de forças para a consecução de um objetivo comum; a paralisação de um jogo para atender o adversário que estava ao chão. Estes elementos demonstram como não devemos desprezar as atitudes realizadas autonomamente pela criança, as quais são fundamentais para a construção de sua personalidade. Contudo, na esfera escolar não se deve permanecer neste espaço relacional. É preciso partir destas relações, mas não ficar preso a elas, transcendendo-as para esferas humanas genéricas, como ressalta Heller (1991), o que promove uma ressignificação da própria vida cotidiana, realizando uma ponte entre a teoria e a prática. Assim, objetivamos mostrar que a intervenção docente, posteriormente a observação dos elementos surgidos nas atividades "livres", possibilita a transformação da prática pedagógica em práxis pedagógica, a qual materializa um processo educacional crítico-emancipatório.

Os dados coletados em nosso trabalho demonstram que a transformação das manifestações preconceituosas expressas por pré-escolares pode ser efetivada pela interrelação de cinco elementos: a) consideração de qualquer fenômeno social como historicamente construído; b) valorização das diferenças e das mais diversas culturas apresentadas pelas crianças; c) edificação de objetivos não atrelados ao rendimento atlético nas atividades lúdicas escolares; d) experimentação de uma grande multiplicidade de movimentos corporais por todas as crianças; e) construção de relacionamentos mais cooperativos durante a prática lúdica.

Assim, a escola pode visualizar formas de sociabilidade pautadas em relações cooperativas entre distintas culturas e se posicionar, favoravelmente, na luta pelo reencontro do indivíduo com a humanidade. Por isso, ao invés de um sistema que reconcilia como fato natural a existência da felicidade particular, em correlação à infelicidade geral, devemos construir situações humanas em que a felicidade de um represente o bem estar de todos e vice-versa, ou seja, um sistema em que coletividade e individualidade não estejam analogamente em oposição, mas em complementaridade.

Esta relação de complementaridade só se consegue nos ambientes escolares quando, além de criticarmos a naturalização dos "conceitos" e constructos humanos - nos posicionando favoravelmente à cooperação -, não marginalizarmos a competição que, historicamente, tem possibilitado aos homens se desenvolverem em diversas áreas, desde que esta não se transforme em uma forma de segregação e exclusão do outro, da diferença. A contradição dialética deste processo é experimentada no estádio pré-escolar mediante, fundamentalmente, as atividades lúdicas, pois nelas o contato entre o coletivo e o individual, o externo e o interno, a competição e a cooperação, se estabelece por excelência; por intermédio de sua prática, a criança se apropria dos conhecimentos produzidos por todo o gênero humano e, por isso, deve constantemente ser estimulada. 
Devido à conjunção destes elementos, as atividades lúdicas não podem ser encaradas como meros passatempos, pois, ainda que em certas ocasiões gerem alegria e diversão descompromissadas, na grande maioria das vezes é por meio de sua prática que os pré-escolares se enraízam nas esferas sociais, culturais e educacionais, de forma radical e histórica. Estas atividades se arquitetam mediante um complexo sistema de relações sociais, contendo em gérmen as principais qualidades e contradições codificadas, simbólica e materialmente, no seio das mais diversas práticas cotidianas. Apenas posteriormente, no processo educacional dos pré-escolares, o externo se internaliza, o coletivo se individualiza.

\section{Considerações finais}

Nem sempre a inserção da criança ao universo cotidiano, engendrada mediante a prática de jogos e brincadeiras, traz consigo a compreensão da totalidade de relações sociais constituintes deste universo e expressas na estrutura da própria atividade. Tal como temos a faculdade de produzir a história sem consciência de estarmos fazendo isso, também podemos praticar diversos jogos sem compreendermos seu intricado sistema de regras. Nessas circunstâncias, as atividades lúdicas representam um meio de conformação acrítica à realidade externa, pois "todo jogo é um complexo ininteligível até que compreendamos suas regras" (Thompson, 1981, p. 169). Aqui, a necessidade de mediações se faz presente de forma cristalina, principalmente no campo da educação sistemática, uma vez que sem a compreensão dos elementos que edificam determinado sistema social, simbólico ou lúdico, qualquer possibilidade de transformação de sua estrutura se apresenta seriamente comprometida.

Somente após este processo de conhecimento, que também o é de autoconhecimento, podemos objetivar a construção de uma nova forma de realidade cotidiana, inclusive com o redimensionamento das antigas relações sociais e de novas estruturas constituintes das atividades lúdicas, as quais permitam que seus participantes visualizem a diferença como um elemento basilar na configuração do gênero humano.

No arcabouço deste complexo processo formativo cabe frisar que o homem, como ser fundamentalmente social e coletivo, só se conhece a si mesmo quando está em relação com a diferença. Por isso, para Marx e Engels (apud Vygotsky, 2000, p. 14), "apenas referindo-se ao homem Paulo como semelhante a si, o homem Pedro começa a relacionar-se com si mesmo, como uma pessoa". Assim, conhecer é situar-se e estar em constante relação com a diferença, a qual nos enriquece desde os primeiros passos dados neste solo histórico. 
Por essas e outras razões, na pré-escola, é de suma importância a utilização de atividades lúdicas diversificadas com as crianças, objetivando que estas possam refletir a realidade sob diversos prismas e desenvolver uma gama de novas potencialidades cognitivas, sensitivas e motoras, as quais não podem surgir espontaneamente, mas apenas com o auxílio de um mediador externo, geralmente concretizado pela intervenção docente, conforme demonstrou nossos dados. A intervenção mediadora docente permite às crianças se relacionarem na chamada "zona de desenvolvimento proximal", possibilitando a vivência de novos desafios e a ampliação qualitativa de sua introdução no solo histórico da humanidade; além disso, edifica ferramentas que situam e contestam as contradições e estereótipos colocados em movimento durante a realização dos jogos e brincadeiras, muitos dos quais são imperceptíveis aos olhos das crianças, quando estas não são levadas a visualizar criticamente as características estruturais da sociedade da qual fazem parte.

Coerentemente, a partir das análises teóricas e dos apontamentos retratados pela prática dos pré-escolares, o jogo em nosso trabalho representa uma interessante união entre teoria e prática. No jogo, o trabalho físico e corpóreo se intelectualiza, a atividade externa se interioriza e o trabalho intelectual se reveste de interessantes contornos manuais e materiais.

Assim, apesar de termos consciência da impossibilidade de a educação modificar isoladamente as situações opressivas nas quais estão imersos os seres humanos, defendemos a prática pedagógica voltada para a transformação da sociedade. Por isso, não coadunamos com qualquer postura de omissão quanto ao papel desempenhado pelo conhecimento na transformação dos homens e mulheres, tampouco defendemos que as mais diversas instituições esperem pela alteração radical da estrutura material para poder executar um trabalho efetivamente democrático na construção de novas relações comunicativas entre os seres humanos. Educar democraticamente é sempre um movimentar-se rumo à liberdade, nem sempre palpável, mas em contínuo processo de construção, pois nossa história não se encontra concluída, é história em devir, inacabada e, por isso, humana.

\section{Referências}

BASTIDE, R; FERNANDES, F. (Dir.). Relações raciais entre negros e brancos em São Paulo: ensaio sociológico sobre as origens, as manifestações e os efeitos do preconceito de cor no município de São Paulo. São Paulo: unesco; AnHembi, 1955.

DAVIDOV, V. La enseñanza escolar y el desarrollo psíquico: investigación psicológica teórica y experimental. Moscou: Progresso, 1988. 
ELKONIN, D.B. Sobre el problema de la periodización del desarrollo psíquico en la infancia. In: Davidov, V; Shuare, M. (Org.). La psicología evolutiva y pedagógica en la URSS (antologia). Moscou: Progresso, 1987. p. 125-142.

ELKONIN, D.B. Psicologia do jogo. São Paulo: Martins Fontes, 1998.

FERREIRA, A.B.H. Novo dicionário de língua portuguesa. 2. ed. Rio de Janeiro: Nova Fronteira, 1986.

HELLER, A. O cotidiano e a historia. 4. ed. São Paulo: Paz \& Terra, 1970.

HELLER, A. Sociologia de la vida cotidiana. Barcelona: Península, 1991.

JONES, J.M. Racismo e preconceito. São Paulo: Edgard Blucher, 1973.

LEONTIEV, A.N. O desenvolvimento do psiquismo. Lisboa: Livros Horizonte, 1978a.

LEONTIEV, A.N. Actividad, conciencia y personalidad. Madrid: Ciências del Hombre, 1978b.

LEONTIEV, A.N. Os princípios psicológicos da brincadeira pré-escolar. In: VyGOTSKY, L.S.; Leontiev, A.; LuRIA, A.R. Linguagem, desenvolvimento e aprendizagem. 4. ed. São Paulo: Ícone, 1988. p. 119-142.

MARX, K. Critica del programa de Gotha. Santiago: Quimantu, 1972.

MARX, K. Manuscritos econômico-filosóficos e outros textos escolhidos. 4. ed. São Paulo: Nova Cultural, 1987.

MARX, K. O Capital: crítica da economia política. São Paulo: Nova Cultural, 1996. v. 1.

SOUZA, E.S.; ALTMANN, H. Meninos e meninas: expectativas corporais e implicações na educação física escolar. Cadernos CEDES, Campinas, v. 19, n. 48, p. 52-68, ago. 1999.

THOMPSON, E.P. A miséria da teoria: ou um planetário de erros - uma critica ao pensamento de Althusser. Rio de Janeiro: Zahar, 1981.

VYGOTSKI, L.S. Obras escogidas. Madrid: Aprendizaje Visor, 1993. v. 2.

VYGOTSKI, L.S. Obras escogidas. Madrid: Aprendizaje Visor, 1995. v. 3.

VYGOTSKY, L.S. Manuscrito de 1929. Educação \& Sociedade, Campinas, v. 21, n. 71, p. 22-44, jul. 2000. 
VYGOTSKY, L.S. A construção do pensamento e da linguagem. São Paulo: Martins Fontes, 2001.

VYGOTSKY, L.S. Teoria e método em psicologia. 3. ed. São Paulo: Martins Fontes, 2004.

Recebido em setembro de 2008.

Aprovado em agosto de 2009. 